\title{
How Do Manufacturing Enterprises Construct E-Commerce Platforms for Sustainable Development? A Case Study of Resource Orchestration
}

\author{
Jingbo Hu ${ }^{1}$, Taohua Ouyang ${ }^{2, *}$, William X. Wei ${ }^{3}$ and Jiawei Cai ${ }^{4}$ \\ 1 School of Business Administration, Jiangxi University of Finance and Economics, Nanchang 330013, China; \\ jing_bohu@yeah.net \\ 2 School of Economics and Management, Beihang University, Beijing 100191, China \\ 3 School of Business, MacEwan University, Edmonton, AB T5J 2P2, Canada; weix@macewan.ca \\ 4 School of Economics and Management, Beijing Jiaotong University, Beijing 100044, China; \\ 19120689@bjtu.edu.cn \\ * Correspondence: taohuaouyang@buaa.edu.cn
}

Received: 13 July 2020; Accepted: 14 August 2020; Published: 17 August 2020

check for updates

\begin{abstract}
The existing literatures mainly focus on the pricing, strategic significance and sustainable development characteristics of the e-commerce platform, and lack deep research on mechanisms in the process of construction like main structure of recourses and driving force. This paper takes Haier as a Chinese example and explores how manufacturing enterprises create and develop the sustainable e-commerce platform. The research findings show that: (1) An e-commerce platform respectively carries the functions of sales channels, service differences and innovation incubation in different stages of the manufacturing enterprises' sustainable development; (2) For managing e-commerce platform of manufacturing enterprises' sustainable development, resource orchestration can effectively realize the integration of value creation and resource; (3) Finally, it further reveals that the driving power which resource orchestration continuously promotes for the sustainable e-commerce platforms to construct is from the co-creation value of manufacturers and users. This paper discusses the structure of e-commerce platforms based on the main characteristics of each resource, and systematically explores the mechanism and evolutionary driving force of resource orchestration to promote the construction of e-commerce platforms for the sustainable development. It complements and enriches the innovation ecosystem and resource orchestration theory, providing significant practical guidance to the sustainable development of manufacturing enterprises.
\end{abstract}

Keywords: e-commerce platform; resource orchestration; sustainable development; construction mechanism

\section{Introduction}

Due to the pressure of sales channels and increasing personalized user needs, many manufacturing enterprises begin to transform into electronic commerce ("e-commerce"), and establish sustainable e-commerce platforms to communicate with users, suppliers, makers and other relevant organizations to improve their understanding of user needs, products and services [1]. With the significant environmental changes in the sustainable development of the manufacturing industry, the world crosses from the 3.0 era of electronic information manufacturing industry into the 4.0 era of intelligent and digital manufacturing industry. Chinese manufacturing enterprises usher great opportunities in transformation, upgrading and sustainable innovation. For example, enterprises like Haier play the leading role of the world in home appliances and communication equipment by establishing various e-commerce sales and sustainable innovation platforms [2]. The reason is that e-commerce 
platforms promote the emergence of a new market business model for the sustainable development. The platform is not only the foundation to support and connect the front end, but also the fertile soil to generate rich sustainable ecology. Discovering and determining the relationship with the platform, and then cultivating or adapting to the platform ecology, is undoubtedly one of the important strategies for the manufacturing enterprise's sustainable development in the future [3,4].

A platform is a two-sided market with network effect since ancient times. For the sustainable development, it changed from the early agricultural market connecting buyers and sellers to an ecological-featured multilateral platform that involves different groups, such as suppliers, manufacturers, customers and intermediary service providers which trust and cooperate with each other [5,6]. Taking sustainable e-commerce platforms as examples, e-commerce giant Alibaba connects buyers and sellers, and manufacturing enterprises like GREE, TCL and Haier also build e-commerce platforms for users and other organizations to incubate innovation. Therefore, "e-commerce platform" has attracted more and more attention from academia and the manufacturing field, in which the content mainly includes the function of the sustainable e-commerce platforms, key factors of success, characteristics of each stage and related financial, logistics, and credit mechanisms [7]. However, most of the research about internet manufacturing enterprises such as Alibaba and Tencent, only discuss the innovation management challenges and strategic characteristics of the sustainable platform ecosystem [8,9], and seldom deeply analyze the development process mechanism of e-commerce platforms.

As more and more manufacturing enterprises are trying to become the Internet enterprises represented by e-commerce platforms, the main problems their transformation and upgrading are faced with is to realize value creation effectively, as well as adjustability of resource management for the sustainable development. Some researchers studied e-commerce platforms from the perspective of resource-based theory (RBT), and believed that the unique core resources of manufacturing enterprises are valuable, rare, inimitable and hard to copy, and constitute the key elements for manufacturing enterprises to compete in an e-commerce strategy. However, manufacturing enterprises are becoming increasingly difficult to have absolute advantages by their unique recourses in the dynamic changes of the market. Sirmon et al. [10] argue that resources must go through accumulation, development, integration and coordination; that is to say, only resources which are effectively managed can create sustainable competitiveness in a dynamic environment, and they then put forward the "resource orchestration" theory. The theory emphasizes that in a dynamic environment managers have to constantly integrate resources, construct capabilities, and use these capabilities to create value, so as to achieve sustainable competitive advantages. However, there are only few studies on e-commerce platforms from the perspective of "resource orchestration", and the research on how manufacturing enterprises develop sustainable e-commerce platforms through resource orchestration still has not been deeply discussed.

E-commerce platforms that this paper focuses on are the new challenge and opportunity to manufacturing enterprises' sustainable development in the current era. Through the sustainable development of e-commerce platforms, Haier has also expanded its brand influence and increased profits. In addition, based on the sustainable development of e-commerce platforms, Haier has promoted the platform transformation of manufacturing enterprises and formed a strong platform ecosystem. Therefore, this paper studies from the perspective of resource orchestration theory, and takes the Haier group as the case study object to deeply discuss the sustainable development process mechanism. The specific research problems include: Firstly, what are the structural characteristics of sustainable e-commerce platforms formed by resource subjects under the "Internet +"? Secondly, how does resource orchestration construct an e-commerce platform and what is the driving force for the manufacturing enterprise's sustainable development? 


\section{Literature Review}

\subsection{E-Commerce Platform for the Sustainable Development: Concept and Construct Research}

"Platform" originally referred to a two-sided market, characterized by network externalities and competitions [11]. In other words, there are generally participants on both sides, and the final profit is generated by the interaction of participants on the same platform [12]. However, with the sustainable development of manufacturing enterprises' information technology, the application of the platform is not only limited to two sides of participants, and the two-sided platform has been extended to a platform ecosystem, including participants of different groups, such as suppliers, manufacturers, customers, intermediary service providers and platform complementary persons [13,14]. An e-commerce platform is a two-sided or even multi-sided market with endogenous side decisions [15], which connects buyers, sellers, suppliers, complementary parts suppliers and other relevant resources for the sustainable development [16].

As the Internet and online shopping matured in the China market, other related institutions from different industries such as finance, logistics, telecoms and software services began to gather by revolving around the users' needs in a sustainable e-commerce platform. These institutions are connected by the Internet, promoting and driving each other, building the sustainable ecosystem with the scale profits and competitive advantages. A large e-commerce platform like Alibaba has constructed huge ecosystems after attracting the participation of many professional suppliers, financial institutions, software service providers and logistics institutions [17]. The two or more sides of participants of the platform do not only accomplish their own tasks, but also share resources and complement each other for the manufacturing enterprise's sustainable development [18].

At present, the research on the construction of a sustainable e-commerce platform mainly has the following characteristics: First, a large number of existing literatures focus on the price mechanism of the sustainable platform of Internet manufacturing enterprises, and believe that the platform will develop effectively through the network effect as long as it has an appropriate price mechanism [19]; second, focus on the strategic significance of e-commerce for service-oriented manufacturing enterprises' sustainable development, or specifically on the construction of logistics, finance and marketing related to e-commerce [20]; third, in the study on the evolution of the ecological construction of e-commerce platforms, pay more attention to the sustainable development characteristics of each stage, or specificities of each stage and the promotion and hindrance factors [21]. Therefore, the existing literature lacks in-depth studies on the main structure, mechanism and driving force of the construction process of e-commerce platforms of manufacturing enterprises' sustainable development.

\subsection{Resource Orchestration for the Sustainable E-Commerce Platform}

People and things that enable a manufacturing enterprise to improve the sustainable e-commerce platform operating efficiency and receive ultimate benefits all belong to the resources. It includes organizational process, organizational structure and information of manufacturing enterprises' sustainable e-commerce [22]. In other words, the sustainable resources of manufacturing enterprises are the forces that they can use to formulate and implement their strategies. Resource-based theory holds that the unique core resources, which are valuable, scarce, inimitable and hard to copy, are the source for manufacturing enterprises to obtain sustainable competitive advantages [23]. However, the sustainable development of manufacturing enterprises not only need unique e-commerce heterogeneous resources, but also need to constantly integrate resources and construct capabilities to cope with the drastic changes of e-commerce platforms [24].

Due to the uncertainty of the dynamic environment caused by fluctuation of market demands and change of the sustainable e-commerce platform, Sirmon et al. [25] proposed the theory of resource management, and explained the three components of resource management process in detail: structuring the resource portfolio, bundling resources to build capabilities, and leveraging capabilities to create value. Meanwhile, Helfat et al. [26] proposed the asset orchestration framework, which 
mainly contains search and selection, collocation and deployment, cultivation and innovation, etc. Although resource management and asset orchestration both focus on managers' behaviors and how these behaviors affect the sustainable development of manufacturing enterprises and enhance their competitive advantages, resource management lacks a resource deployment strategy and asset orchestration lacks innovation and cultivation based on resource integration [27]. Accordingly, Sirmon et al. [10] proposed the resource orchestration theory according to the similarity and complementary character of resource management and asset orchestration in Figure 1, and believed that resource management is also important in fostering innovation capabilities to create sustainable value for manufacturing enterprises.

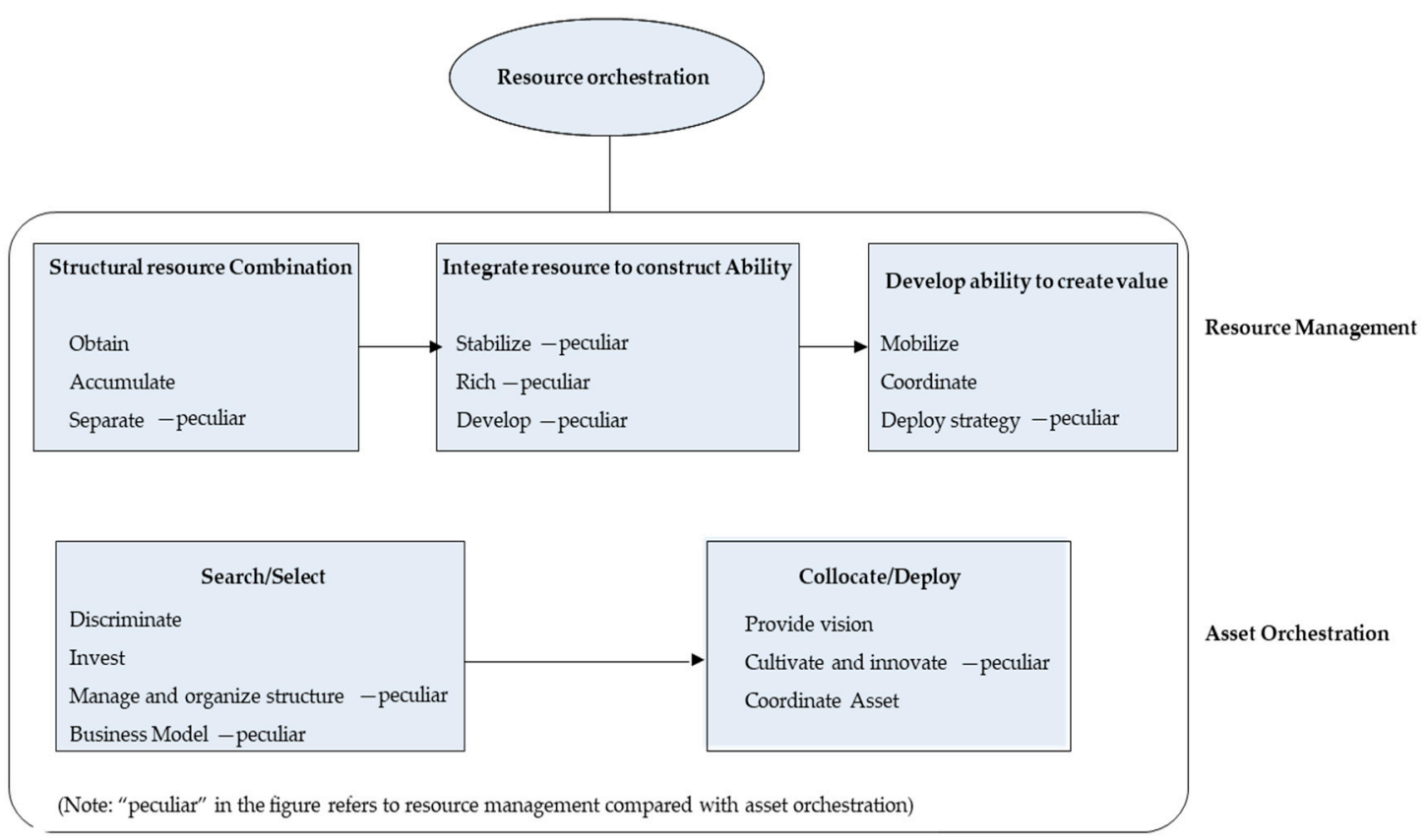

Figure 1. Difference of resource orchestration, resource management and asset orchestration.

Resource orchestration theory well connects uncertain environment and capabilities, and refines several components of the resource strategic management process. To cope with the dynamic environment, the sustainable development of manufacturing enterprises need to construct e-commerce platforms through resource orchestration such as obtaining, transforming, coordinating and other behaviors based on cooperation and innovation of resource subjects [28].

Therefore, studying e-commerce platforms from the perspective of "resources orchestration" with dynamic environments and managerial behaviors will greatly facilitate the in-depth study of the mechanisms and evolutionary dynamics of e-commerce platform ecosystems.

\subsection{Theoretical Analysis Framework}

Above all, because of the limitations of the existing researches and the fact that the manufacturing enterprises are undergoing transformation and upgrading by developing e-commerce platforms, the writers expect a breakthrough in this paper by exploring the construction of sustainable e-commerce platforms from a new theory-based perspective. This paper could break through the existing research limitations and explore the construction of sustainable e-commerce platforms from a new theory-based perspective. This paper is based on the perspective of resource orchestration theory and combines with the market environment of Haier group's sustainable e-commerce platform construction. For the sustainable development of manufacturing enterprises, internal and external resource combination and construction ability are mutually improved to promote the construction of an e-commerce platform. This paper follows the structural logic of inducement-process-result, and then refines 
the theoretical analysis framework (see Figure 2). By analyzing the framework, this paper attempts to establish the process mechanism of sustainable e-commerce platform construction driven by resource orchestration, and explores the internal driving force of its evolution.

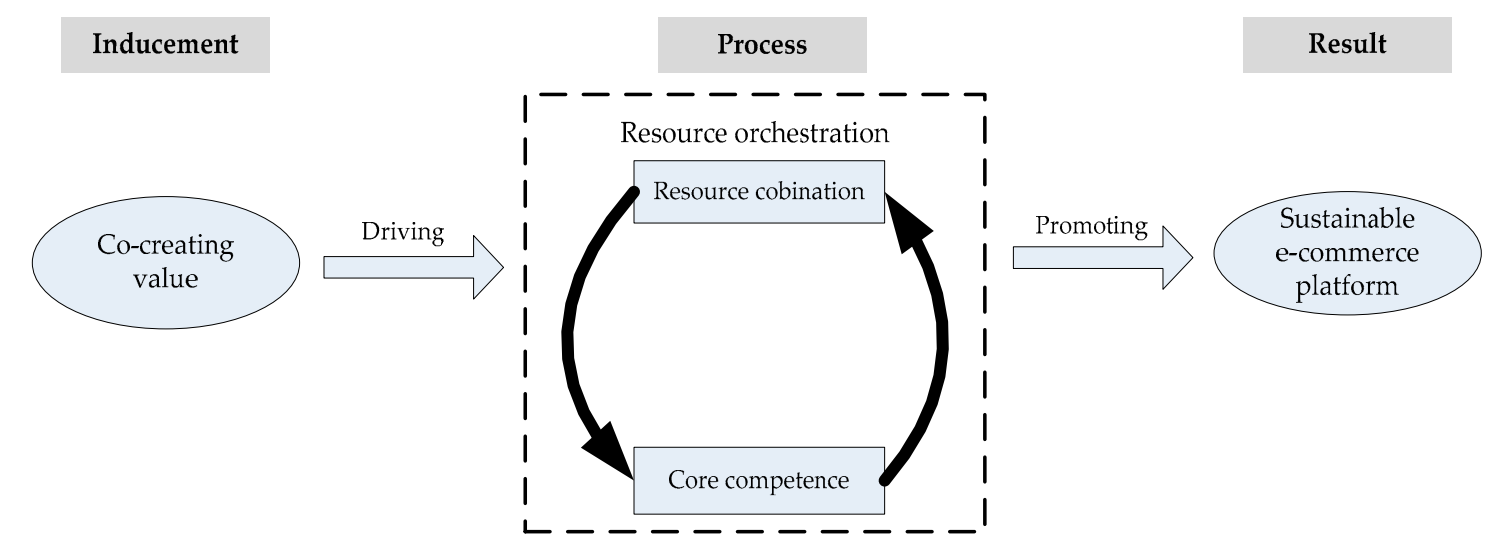

Figure 2. The theoretical analysis framework of this paper.

\section{Analytical Method}

\subsection{Research Methods and Object Selection}

As an empirical method, a case study usually adopts multiple ways such as interviews, observations and reading internal documents of manufacturing enterprises' sustainable development to observe the research subjects. This method emphasizes the fit between the research problems and explains the phenomenon or constructs the theory based on a detailed description of the sustainable development phenomenon [29]. Data fidelity is the basic principle of this method, which enables researchers to maintain an objective attitude in the research process [30]. Due to the varied development level of enterprises and the limitations of relevant researches, the case study method should be more suitable for this research. The reason why the writers chose Haier is that it has the best sustainable development practice which embodies the three principles of case sample selection:

Firstly, the selection of case objects takes into account the principle of importance and representativeness [31]. As the world's largest manufacturer of white goods, Haier has a wide range of products, which covers home appliances, communications, IT digital products and many other fields. Besides their own e-commerce platform Ehaier, Haier has already completed the sustainable cooperation with other third-party e-commerce platforms. The case of Haier's sustainable e-commerce platform reflects the importance and representativeness principles of case selection.

Secondly, the selection of research samples follows the principle of theoretical sampling. The case selected is based on theoretical needs such as expanding emerging theories or complementing gaps in existing theories [32]. Although the literature in the past acknowledged the important role of resources in sustainable e-commerce platforms, few studies have been noticed how the dynamic environment and resource orchestration of managers' behaviors promote the sustainable development of e-commerce platforms. Based on the theory of resource orchestration, this paper explores the sustainable development process of Haier's e-commerce platform and tries to open up the "black box" of how manufacturing enterprises realize the sustainable development of e-commerce platforms through resource orchestration, which is helpful to improve the resource orchestration and e-commerce platform.

Thirdly, the case selection considers the consistency principle of theoretical target and case object. The sustainable development of Haier's e-commerce platform in different stages is accomplished in the process of constantly orchestrating resources and constructing dynamic capabilities according to the rapidly changing market environment. This research team has more than ten years of Haier tracking research experience, and has a deep understanding of the manufacturing enterprise's sustainable 
development in the research case. The process of obtaining the detailed primary and secondary materials of the manufacturing enterprise which are needed in this research also verify this point. Therefore, the sustainable practical and theoretical goals of the manufacturing enterprise in this case are consistent with each other.

\subsection{Data Collection and Analysis}

The data collection and analysis include three phases to ensure reliability and validity, shown in Figure 3. Phase 1 is the preparation to establish reliability during December of 2017 and November of 2019. Previous interview data was studied and the sustainable e-commerce platform development chronological timeline was drawn in February of 2018, followed by the initial interviews and the theoretical lens of resource orchestration selection. Phase 2 engaged in onsite visits from summer vacation in 2018 and 2019. The authors interviewed many middle and senior team members of Haier, refined three different phases, and readjusted the framework. Phase 3 is the follow-up from January to November of 2019. When the interview data was not enough to support theoretical analysis, additional data was collected via phone calls and emails to assure data-theory-model alignment.

\begin{tabular}{|c|c|c|c|c|c|}
\hline \multirow{3}{*}{ Data } & \multicolumn{2}{|c|}{ Phase 1: Preparation } & \multicolumn{2}{|c|}{ Phase 2: Onsite Visits } & Phase 3: Follow-up \\
\hline & \multirow{2}{*}{\begin{tabular}{|l||} 
May 2017 \\
Reviewed \\
previous interview \\
data in Jun 2016 \\
and gathered \\
secondary data
\end{tabular}} & $\begin{array}{l}\text { Jan. } 2018 \\
\text { Held initial } \\
\text { interviews with } \\
\text { the gatekeeper }\end{array}$ & \multirow{2}{*}{\multicolumn{2}{|c|}{$\begin{array}{l}\text { Aug. } 2018 \\
\text { Interviewed with Spacesat's } \\
\text { internal development, supplier } \\
\text { network and partner } \\
\text { universities }\end{array}$}} & \multirow[t]{2}{*}{$\begin{array}{l}\text { May } 2019 \\
\text { Supplemented and confirmed } \\
\text { via phone calls and emails }\end{array}$} \\
\hline & & & & & \\
\hline \multirow{5}{*}{$\begin{array}{l}\text { Data } \\
\text { Analysis }\end{array}$} & \multirow{3}{*}{$\begin{array}{l}\text { Aug. } 2017 \\
\text { Drew chronological } \\
\text { timeline of Spacesat's } \\
\text { sustained innovation } \\
\text { with external and } \\
\text { internal cooperation }\end{array}$} & \multirow{3}{*}{\begin{tabular}{l|} 
July 2018 \\
Selected \\
ambidextrous \\
capability as \\
the theoretical \\
lens
\end{tabular}} & \multirow{2}{*}{$\begin{array}{l}\text { Dec. } 2018 \\
\text { Divided interview } \\
\text { data into three } \\
\text { different phases }\end{array}$} & \multirow{2}{*}{$\begin{array}{l}\text { Apr. } 2019 \\
\text { Readjusted the } \\
\text { preliminary } \\
\text { theoretical } \\
\text { framework }\end{array}$} & $\begin{array}{l}\text { Supported theoretical constructs } \\
\text { and processes with axial coding }\end{array}$ \\
\hline & & & & & \multirow{2}{*}{$\begin{array}{l}\text { Dec. } 2019 \\
\text { Assured data-theory-model } \\
\text { alignment with informants and co- } \\
\text { researchers }\end{array}$} \\
\hline & & & & & \\
\hline & $\downarrow$ & 1 & 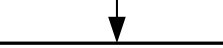 & $\downarrow$ & $\nabla$ \\
\hline & \multicolumn{2}{|c|}{ May 2017-July 2018} & \multicolumn{2}{|c|}{ Aug. 2018-Apr. 2019} & May 2019-Dec. 2019 \\
\hline \multicolumn{3}{|c|}{ Measures to Establish Reliability } & \multicolumn{3}{|c|}{ Measures to Establish Validity } \\
\hline $\begin{array}{l}-\quad \mathrm{C} \\
-\quad \mathrm{r} \\
-\quad \mathrm{I} \\
-\quad \mathrm{r} \\
\mathrm{r}\end{array}$ & \multicolumn{3}{|c|}{$\begin{array}{l}\text { Collected data from secondary sources to refine } \\
\text { related research topics } \\
\text { Prepared a semi-structured interview guideline that } \\
\text { was theoretically relevant } \\
\text { Recorded and checked interview transcripts to } \\
\text { assure the accuracy and integrity of case data }\end{array}$} & \multicolumn{2}{|c|}{$\begin{array}{l}\text { Established an interview team of ten researchers: } \\
\text { one asked questions and others also took notes } \\
\text { - Discussed theoretical ideas in the team and } \\
\text { presented models to informants } \\
\text { - Ensured process theory was supported by data and } \\
\text { literature }\end{array}$} \\
\hline
\end{tabular}

Figure 3. Overview of research methods.

\subsubsection{Data Collection}

This paper follows the process of case study: "Clarify Research Problems $\rightarrow$ Literature Review $\rightarrow$ Case Study Draft Design $\rightarrow$ Data Collection $\rightarrow$ Data Analysis" [33]. The paper also finds out theoretical innovation points through the cycle analysis and repeatedly focuses on theoretical and data [34]. The data sources of this study include personnel interviews, field observation and literature materials. The multi-channel sources can make the research data supplement and cross-verify each other, thus avoiding the deviation caused by the single information collection channel, and improving the construction validity. The data collection sources of this paper mainly include the following three aspects:

The first is interview and research. The research team made a total of 4 times comprehensive field interviews in 2017. The interview content is in Table 1. The main interview objects are the mid-level managers and related department staff of Haier group's sustainable development. The interview uses 
a semi-structured model and the duration of each is at least $1 \mathrm{~h}$ and, at most, $2.5 \mathrm{~h}$. All the interviews are recorded, and the interview records are finally organized for nearly 200,000 words.

Table 1. Overview of formal interview with Haier.

\begin{tabular}{|c|c|c|}
\hline Interview Theme & Interviewees & Main Content \\
\hline \multirow{3}{*}{$\begin{array}{c}\text { Virtual and Real } \\
\text { Integration of Electronic } \\
\text { Commerce } \\
\text { Sustainable Business } \\
\text { Strategy }\end{array}$} & Strategy Department of E-mail & $\begin{array}{c}\text { Background, positioning and planning } \\
\text { proposed by Haier sustainable } \\
\text { development }\end{array}$ \\
\hline & Strategy Department of Group & $\begin{array}{c}\text { Integration issue of Haier's virtual net } \\
\text { and real net }\end{array}$ \\
\hline & $\begin{array}{l}\text { Executive Vice President of } \\
\text { the Group }\end{array}$ & $\begin{array}{c}\text { Change of channels, confusion of Haier } \\
\text { and the integration of people and orders } \\
\text { in the process of sustainable } \\
\text { development }\end{array}$ \\
\hline $\begin{array}{l}\text { Marketing System which } \\
\text { Supports the Virtual and } \\
\text { Real Integration of } \\
\text { Sustainable E-Commerce }\end{array}$ & $\begin{array}{l}\text { Operating System of Haier, } \\
\text { the Operating System of } \\
\text { Integration of Virtual and Real }\end{array}$ & $\begin{array}{l}\text { Issue of Haier's multi-point contact, } \\
\text { integration of virtual net and real net }\end{array}$ \\
\hline $\begin{array}{l}\text { Logistics, Service System } \\
\text { which Supports } \\
\text { the Virtual and Real } \\
\text { Integration of } \\
\text { Sustainable E-commerce }\end{array}$ & $\begin{array}{l}\text { Interface of Logistics Business } \\
\text { E-commerce, Interface of Service } \\
\text { Business E-commerce }\end{array}$ & $\begin{array}{l}\text { Independent management, interface } \\
\text { issue of service, transformation of } \\
\text { sustainable internal system; core follow } \\
\text { of logistics, issue of } 24 \mathrm{~h} \text { and the last } \\
\text { kilometer }\end{array}$ \\
\hline \multirow{3}{*}{$\begin{array}{c}\text { Informatization of } \\
\text { Sustainable E-commerce } \\
\text { Platform }\end{array}$} & $\begin{array}{l}\text { Mechanism Innovation } \\
\text { Management }\end{array}$ & $\begin{array}{c}\text { Challenges to PSI and node organization } \\
\text { by sustainable network strategy }\end{array}$ \\
\hline & $\begin{array}{l}\text { Virtual and Real Integration } \\
\text { Operation, Interface of Logistics } \\
\text { and Service }\end{array}$ & $\begin{array}{l}\text { E-commerce sustainable development } \\
\text { stage, mass customization }\end{array}$ \\
\hline & $\begin{array}{l}\text { E-commerce Department of White } \\
\text { Home Appliances Group }\end{array}$ & $\begin{array}{l}\text { Transformation of business process in } \\
\text { the context of sustainable e-commerce, } \\
\text { changes brought about by supply chain } \\
\text { system and mechanism }\end{array}$ \\
\hline $\begin{array}{l}\text { Business, Research, } \\
\text { Development, Supply } \\
\text { Chain System Related to } \\
\text { White Home Appliances } \\
\text { and Sustainable } \\
\text { E-Commerce Platform }\end{array}$ & E-mail, Haier Research Center, & $\begin{array}{l}\text { Problem of price, introduction of } \\
\text { external resources, impact of virtual } \\
\text { network on the market, and challenges } \\
\text { under the sustainable network strategy }\end{array}$ \\
\hline
\end{tabular}

The second is field observation. In the process of interview and investigation, the team also observes the case manufacturing enterprises on the spot. In addition, the graduate students we cooperated with in this research have also participated in the internship at Haier Beijing branch in the summer holidays of 2018 and 2019 before graduation. They respectively practiced in the digital marketing center, customer service center and physical stores of Haier. Therefore, they actually had a direct understanding and experience of Haier's sustainable e-commerce and we can obtain direct observation data.

The third is documentation. Another important source of this study is the paper and electronic documents. The second-hand data provide relevant background information of the Haier group, and can verify or falsify the data obtained through other channels. The secondary materials mainly include research literature, data released by national authorities, research reports issued by famous consulting institutions, online media such as the official website, blogs and other relevant information of Haier group's sustainable development. 


\subsubsection{Data Analysis}

In this study, the research team sorted out more than 140,000 words of the interview transcripts and triangulated them according to multiple data sources and multiple interviewees to select credible data for analysis. The team also adopts the method proposed by Corbin and Strauss [35] to encode the collected data, and explores and analyzes the process mechanism of manufacturing e-commerce platform sustainable development based on resource orchestration. The data analysis and coding process in this paper includes the following three steps:

The first one is open coding. In this stage, the team repeatedly reads the materials of manufacturing enterprises' sustainable development, which is related to the case of Haier, and keeps an open mind to accurately grasp the meaning of the interviewees, trying to avoid imposing the literature or researchers' minds on the interview data. In coding, the meaning of each sentence is mainly represented by the interviewee's own words. First-order concepts are mainly formed in this stage, which are usually words repeatedly mentioned by interviewees, such as cooperative subjects, sustainable development stages as well as different structures in e-commerce platforms.

The second one is spindle coding. This stage is mainly based on the researcher's grasp of existing literature such as resource orchestration and e-commerce platform sustainable development, and repeated comparison of interview data to summarize relatively abstract second-order concepts. This stage is a key period for the emergence of new concepts. For example, the second-order concepts of resource organization and core competence in this paper occur in this stage.

The last one is selective coding. In this stage, the team combines relevant literatures and case materials to check all coding data, and refines and integrates all second-order concepts with more accurate concepts, forming summarizing concepts like value creation in the sustainable development process.

Therefore, based on the above coding analysis, the conceptual evolution process of data coding analysis in this paper is reflected in Figure 4.

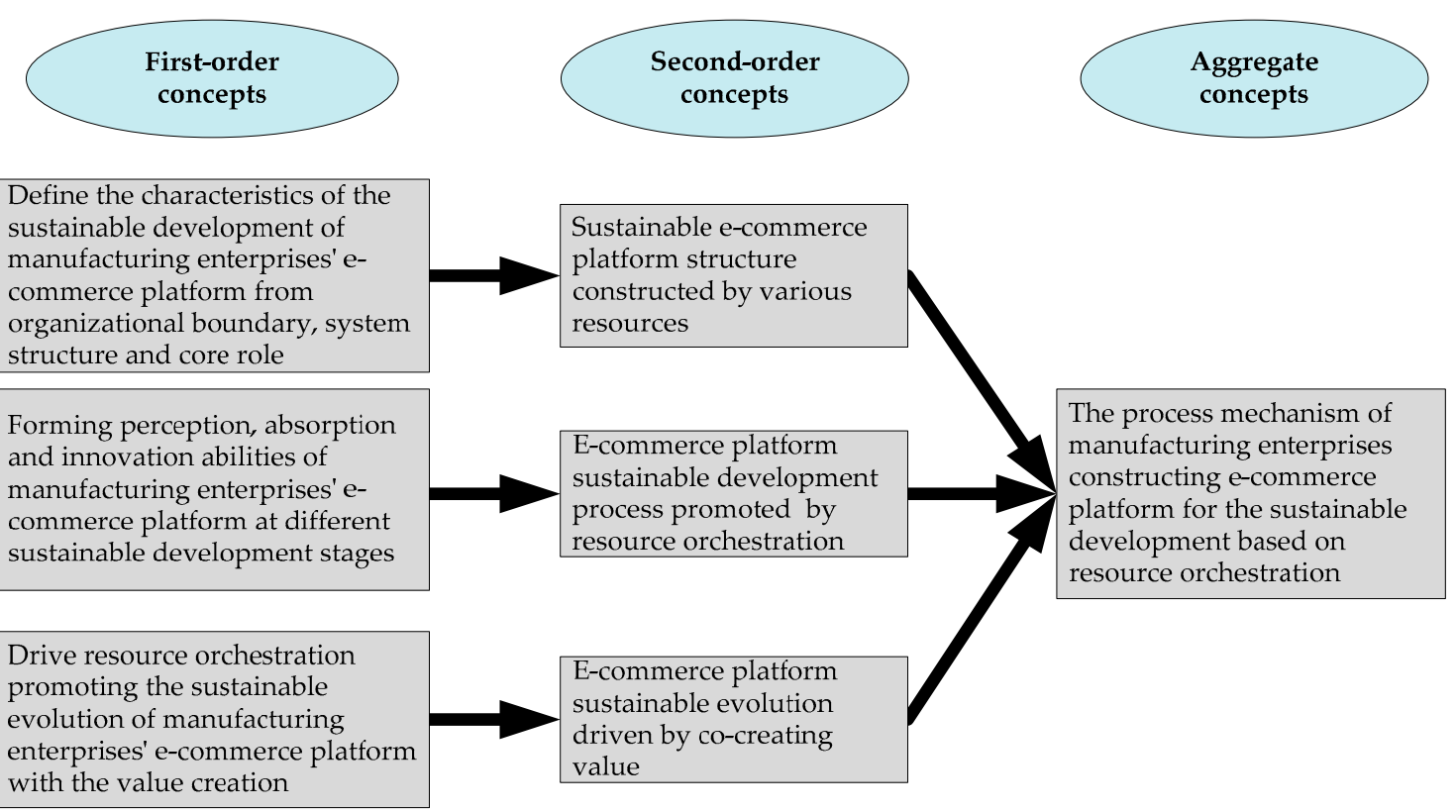

Figure 4. Conceptual evolution process of data coding analysis in this paper.

\section{Case Description and Findings}

Since it was established in 1984, Haier has been adhering to the principle of "user-centered" to drive the continuous and sustainable development of manufacturing enterprises. From the initial stage of brand-name strategy, to the development of diversification, internationalization and globalization 
strategy, it has now entered the stage of sustainable development, and started a new attempt to transform manufacturing enterprises in the Internet era-from manufacturing products to manufacturing maker's platforms. From the ordinary home appliance manufacturer to the current world-class large manufacturing enterprise, the sustainable development of Haier's e-commerce is proceeding simultaneously. From the service differences of the single sales function, delivery and installation in 2000 to the platform ecosystem of innovation incubation, Haier has experienced nearly 16 years of sustainable development. The key events in its sustainable development process of the e-commerce platform are shown in Figure 5.

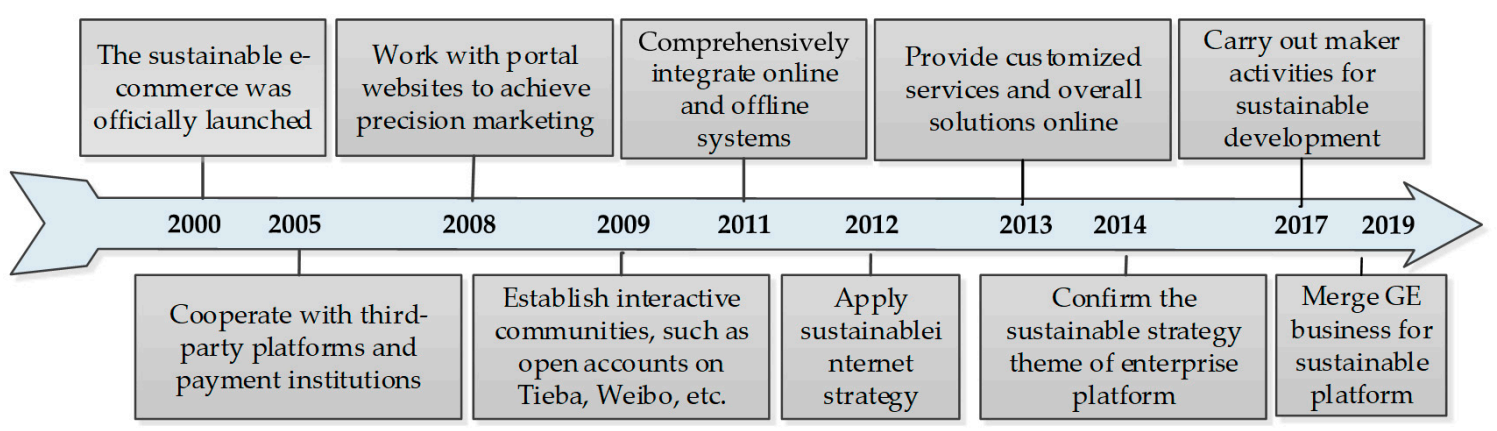

Figure 5. Key events in the development of Haier's e-commerce platform.

\subsection{Initial Stage of the Sustainable E-Commerce Platform: Sales Channel}

Since 2000, chain retailers have developed rapidly and have begun to control the sales channels of home appliances. Manufacturers can only improve sustainable sales performance by cooperating with these retailers. The popularity of e-commerce, especially of big-ticket items traded on the Internet, gives manufacturers a chance to break away from the control of chain retail channels. On March 10 of 2000, Haier invested 10 million yuan to set up E-commerce Co. Ltd., on the basis of accumulated experience in the call center, officially launching the sustainable e-commerce project. This is the first e-commerce company in China's home appliance industry. By building its own website, Haier promotes the sustainable development of manufacturing enterprises on the one hand, and increases the strength of product marketing through e-commerce on the other hand. At the beginning, Haier e-commerce was mainly sustainably responsible for receiving online orders, and then delivered to 42 industrial and trade companies nationwide for delivery, installation and maintenance, and exchanged user feedback information through after-sales service.

In 2005, Haier began to cooperate with third-party sustainable e-commerce platforms for selling more products and promptly understanding user needs. In 2008, Haier released information on major web portals including Baidu, and pushed the desired products to users. To ensure smooth online transactions, it also cooperated with China Construction Bank, Industrial and Commercial Bank of China and other commercial banks, as well as the widely used third-party payment platform Alipay, to realize online payment functions.

"Haier cooperated with third-party e-commerce platforms to attract more user groups for our sustainable development; at the same time cooperated with Baidu such a portal to achieve the matching of products and search, precision marketing... Haier has built sustainable e-commerce platforms in various ways, so as to keenly perceiving the needs of the consumer market and making timely sales response according to user needs."

-Vice President of Haier Group 


\subsection{Growth Stage of the Sustainable E-Commerce Platforms: Service Differences}

After the initial stage of sustainable development, Haier's e-commerce platform has basically realized the delivery of various products to users. However, with the growing maturity of the sustainable e-commerce market environment and the continuous increase of user requirements, Haier launched the integration of virtual network and real network (Virtual network is the mobile terminal media realized by information technology, such as telemarketing, television and network shopping. There is also one kind of oldest and most traditional social network, such as word of mouth; Real network refers to the operation network where users can experience and contact products/services), and proposed the differentiation of the sustainable e-commerce platform of 24-hour time-limited delivery, synchronous loading and overtime free-of-charge service.

"The real network and virtual network of Haier is separated at first. But through the virtual-real integration, the sustainable developing resources of physical stores, regarding more than thirty thousand stores as wealth and the analysis of a large amount of data and ask for a lot of user needs, Haier finally implemented differentiation through the way of timely delivery and the final kilometer issue."

\section{-Director of E-commerce Department}

Haier has built its own Gooday logistics company, and achieved seamless coverage of the three and four levels of markets. The nearest community store matched by the sustainable system is responsible for door-to-door delivery, so as to achieve "sales to village, delivery to door and service to buyers". However, through the establishment and upgrading of the company's internal and external systems, Haier finally realized timely information transmission and 6-8 hours' delivery in the center city and 24 hours' delivery in the region. In addition, social platforms began to boom in 2009 and 2010. Haier integrated internal logistics, services, information and other resources on the one hand, and started to create communities, BBS and Weibo to communicate more and deeper with users on the other hand. It not only met the personalized needs of users, but also optimized the internal process of manufacturing enterprises' sustainable development and shortens the supply cycle. With all these, Haier's e-commerce differentiation can cope with market competition more effectively.

\subsection{Development Stage of the Sustainable E-Commerce Platform: Innovation Incubation}

At the beginning of 2012, Ehaier (Ehaier is an e-commerce platform built by Haier itself, which was established in 2002 and started to provide customized services in 2012) started to work on the customization service of home appliances, and launched the personalized customization of TV, air conditioning panel and other products. In 2013, it cooperated with third-party sustainable e-commerce platforms to try many C2B (Customer to Business) customization activities. Haier established five R\&D centers in the world and formed a global network of sustainable innovative resources. At the same time, it established an open online platform, HOPE (HOPE-Haier Open Partnership Ecosystem, which is used to connect experts with top innovation manufacturers in the global innovation network), on which global user resources can realize zero-distance interaction.

Subsequently, Haier put forward the theme of "To improve manufacturing enterprise sustainable development, employee maker (maker refers to people who work to turn ideas into reality with user innovation at core) and user personalization" at the "Internet innovation interaction" conference, and began to transform and develop. At present, the Haier platform only has three types of people-platform owners, small micro owners and makers. The main responsibility of the sustainable platform owners is not controlling but providing service. Small micro owners mainly lead teams to start a business, while employees become makers for entrepreneurship and innovation. As the main body of rapid resource allocation directly to users, the platform provides open resource support for small micro owners. Among them, "Thunderobot" game is a typical case of Haier's innovation incubation of collaborative resources in the transformation stage. "Thunderobot" relied on the channels of Baidu 
Post Bar, BBS, QQ group and other channels to interact with users, and summarized 13 pain spots of users from 300,000 comments, so as to see the product opportunities of gaming laptops. The maker group integrated the resource of external design and internal boundaryless team of the enterprise, and came up with product ideas according to user needs. Then after R\&D and trial production, and after the test of the majority of players, they made reservation sales, and finally improved the product according to the sustainable platform user evaluation feedback, and the final product was delivered in such a cycle.

Therefore, people can interact with users and find new market opportunities through sales with the sustainable e-commerce platform represented by Ehaier and the third-party platform at the same time; obtain funding, policy, and sales support through maker incubation platform represented by Hailifang (Hailfang is the Haier creative crowd funding platform for tapping more professional talents' creativity) and have world-class customized services through R\&D platform represented by HOPE. At the same time, it also creates value around user needs and forms a win-win sustainable e-commerce network in the future.

\section{Case Analysis and Discussion}

Based on the review of the three sustainable development stages of Haier's e-commerce platform, this paper analyzes and discusses the structure characteristics, construction mechanism and internal driving force of the resources constructed by the e-commerce platform.

\subsection{Sustainable E-Commerce Platform Structure of Manufacturing Enterprises Constructed by Various Resources}

With the sustainable development of information technology, the Internet has been as ubiquitous as air and water, and penetrated into all aspects of our life. For business changes, the Internet has changed the trading place, expanded the trading time, enriched the trading categories, reduced the intermediate links and accelerated the trading speed [36]. The sustainable platform promotes the coordination of resource subjects among bilateral or multilateral participants and improves value through cost reduction [37]. In other words, it provides an interactive mechanism that meets the need of innovation of each group by connecting bilateral or multilateral groups to it, and makes profits from it. The core of the platform strategy is to build a sustainable e-commerce platform ecosystem that benefits all parties and the essence of the platform is that multiple members of the organization achieved common growth through continuous resource cooperation [38]. Therefore, from the early 2000s, Haier tried to build an e-commerce platform based on years of accumulated resources. As a platform connecting multiple manufacturing enterprises and users, it realizes the sustainable development of an e-commerce platform from hub type, network type to symbiosis type (as shown in Table 2). The specific analysis is as follows: 
Table 2. Structural characteristics of sustainable e-commerce platform constructed by various resources.

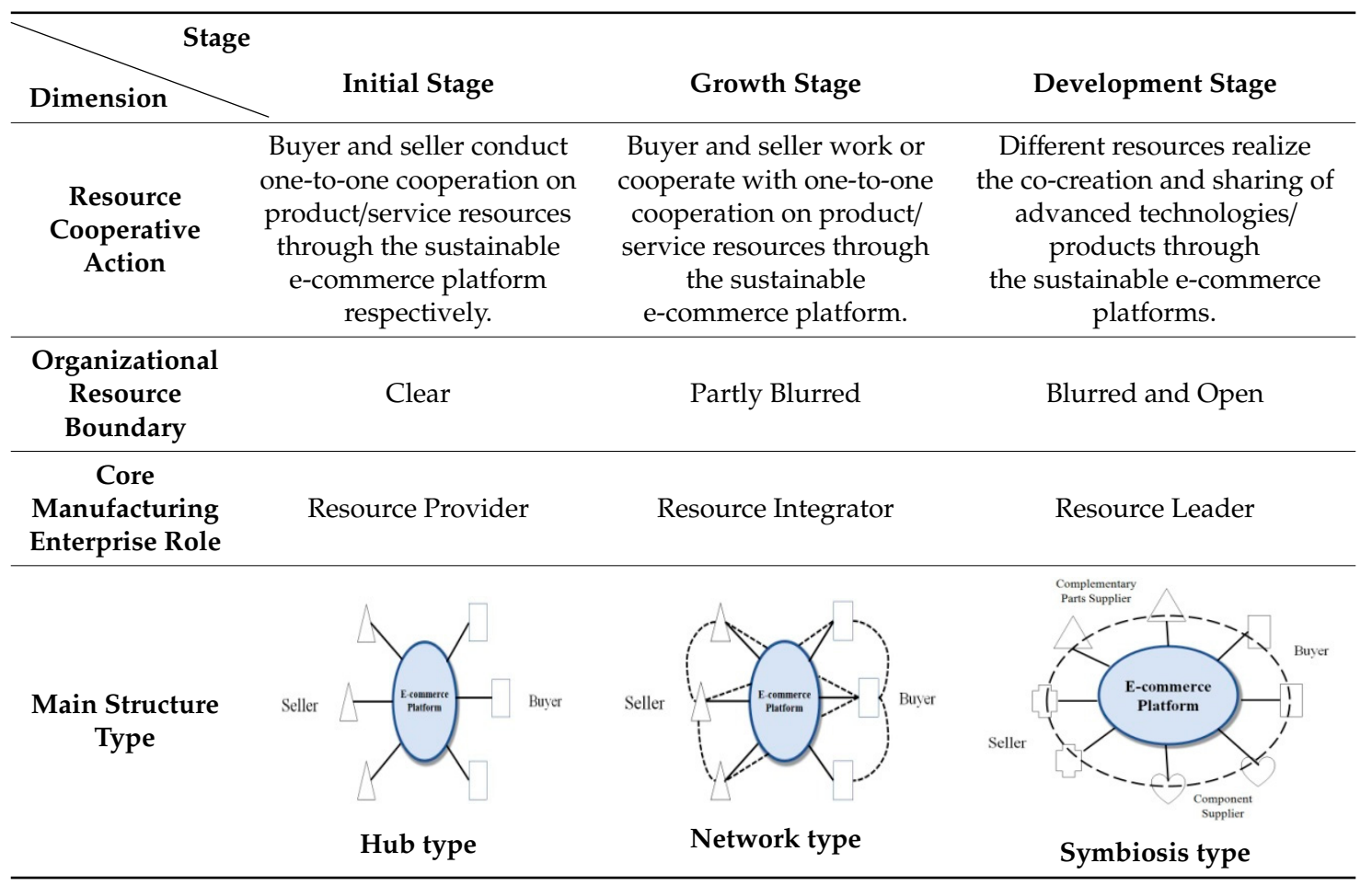

Initial Stage: Haier's e-commerce platform is a resource sales platform connecting products and users. It enables users to know more about various products through the sustainable platform which is convenient for them to purchase and also grows up based on user feedback. At this stage, the sustainable e-commerce platform of Haier only connects the two sides of its own products and users. The related organizational actions are bilateral hubs characterized by single transaction of resource cooperation between seller and buyer and clear organizational boundaries.

"E-commerce is a sustainable platform to communicate with users, and it provides resource channels between manufacturers and users. Internet now actually gives Haier a good mirror for this kind of communication."

\section{—Director of Strategic Planning Department}

Growth Stage: With the gradual maturity of the sustainable e-commerce market in the home appliance industry and the improvement of user demand, Haier integrates resources through internal resource deployment and cooperation with social platforms to expand resources. We can see from the case data, firstly, that Haier achieved internal implementation through the sustainable system. As soon as a customer orders, the production, logistics, services, and other resources can see it and act immediately. The entity store has also become an important member of the sustainable e-commerce platform to participate in the last mile distribution. The internal resources subject boundaries of Haier group gradually became blurred. Secondly, for increasing the interaction between users and crossing the boundary of multiple external organizations, the main external resource of Haier contact with other manufacturing enterprises through the social platform. After the development in this stage, Haier e-commerce carries the integration and cooperation of resources among buyers and sellers, and its platform has formed a network-type e-commerce bilateral sustainable platform.

E-commerce is a good platform to communicate with users. By opening up the internal resource subjects and the external resource subjects of the industrial chain to achieve the integration of the real and the virtual, and also promote the interactive and sustainable development of resources between the buyers and sellers of the platform... 


\section{-Director of Haier e-commerce}

Development Stage: Multi-party participants of e-commerce multilateral sustainable platform promote mutual growth through communication. One party group grows with the increase of demand, which will promote the demand of other groups to grow accordingly, thus establishing a virtuous circle mechanism [39]. In the development stage, Haier's e-commerce platform is a connector between diversified user needs and rich global resources, and mutually symbiotic with designers, suppliers, users, logistics providers, financial institutions and other resources in the sustainable ecosystem. With the help of sustainable e-commerce platform, HOPE platform interacts with users to inform them of desired products or overall solutions. Service personnel of the logistics platform deliver products to users through fast logistics and are satisfactory at last. By providing a sustainable e-commerce platform, Haier realizes the barrier-free access to the co-creation and sharing among organizations, so that the interactive platform of both sides can be built and developed into a symbiotic multilateral sustainable e-commerce platform with internal and external integration.

\subsection{Resource Orchestration Promotes the Construction Mechanism of the Sustainable E-Commerce Platform Development of Manufacturing Enterprises}

To cope with various market environment challenges of e-commerce platforms, core manufacturing enterprises need to continuously integrate resources in resource orchestration to improve the core competence of the sustainable ecosystem [40]. However, in the construction mechanism of a sustainable e-commerce platform, the interaction process of resource coding between core manufacturing enterprises' integration of resources and construction capability will also be different. The existing studies on e-commerce of manufacturing enterprises have already pointed out that integrations of different resources are of great significance for manufacturing enterprises to acquiring core competence [41]. Therefore, in the sustainable development of Haier's e-commerce platform ecosystem, through internal and external mechanisms such as gathering or separating resources according to product orders, user evaluation, and user pay, the construction of the platform ecosystem is promoted.

At the beginning of establishing the sustainable e-commerce enterprise, Haier faced two challenges-chain retailers began to control the sales channels of home appliances, and the online transaction volume gradually increased. In such conditions, Haier established an online sales system on the basis of the original call center and preliminarily built an e-commerce platform to connect enterprises and users. Later, with the sustainable development of the market, Haier built its own e-commerce platform-Ehaier-on the basis of the online sales system. At the same time, Haier also cooperated with external sales platforms. Through the integration of different resources, manufacturing enterprises can quickly perceive the changes of the environment for the sustainable development [42]. Therefore, Haier continuously integrated resources through accumulation of internal IT resources, and access to external sales, payment resource, and platform resource. With the aid of cooperation with search platforms, Haier also constructs its sustainable ability to meet user needs more quickly and accurately while enhancing the ability to perceive user needs.

With the sustainable development of an e-commerce platform, users need faster logistics, better service and more humanized integration of delivery and installation. Haier is mainly to get through the internal and external systems to promote the integration of virtual and real net to meet the market challenges. Haier breaks through the internal "wall", which enables the internal systems such as logistics, service and new order systems to achieve differentiation. By deploying internal logistics resources, Haier achieved 24-h delivery and found a way to meet users' "last mile" needs. At the same time, in order to communicate more and deeper with users, Haier also created accounts on communities, BBS and Weibo to increase user stickiness. At this stage, Haier relies on the perception and response capabilities formed in the initial stage and electric business platform and related resources, perceives market demand for the rapid delivery of users, and integrates the market information. Through the growth stage, manufacturing enterprises combine resources and construct absorptive capacity to improve the efficiency for the sustainable development. 
In the emergence of the "new industrial revolution" characterized by new technologies like "mobile Internet" and "big data", the demands of users become more diverse, and only customized products and overall solutions can satisfy the market environment. Haier is encouraging small and micro teams as the subjects of rapidly gathering resources to "discover market demands and achieve goals through evolution". Through acquiring external resources and transforming user resources, Haier continuously constructs sustainable innovation capabilities, forming a symbiotic platform ecosystem composed of the service platform, logistics platform, supplier platform, and business incubation platform and so on.

At different stages of sustainable development, organizations form different resource combinations by identifying, coordinating and transforming behaviors which are based on resources. Therefore, through the change of related mechanisms to explore user evaluation like "pay stuffs by orders" and "personnel power and distribution power" [43], Haier integrates internal and external resources. It also promotes the sustainable development of e-commerce platforms in the continuous resource orchestration of resource-capability interaction in Figure 6.

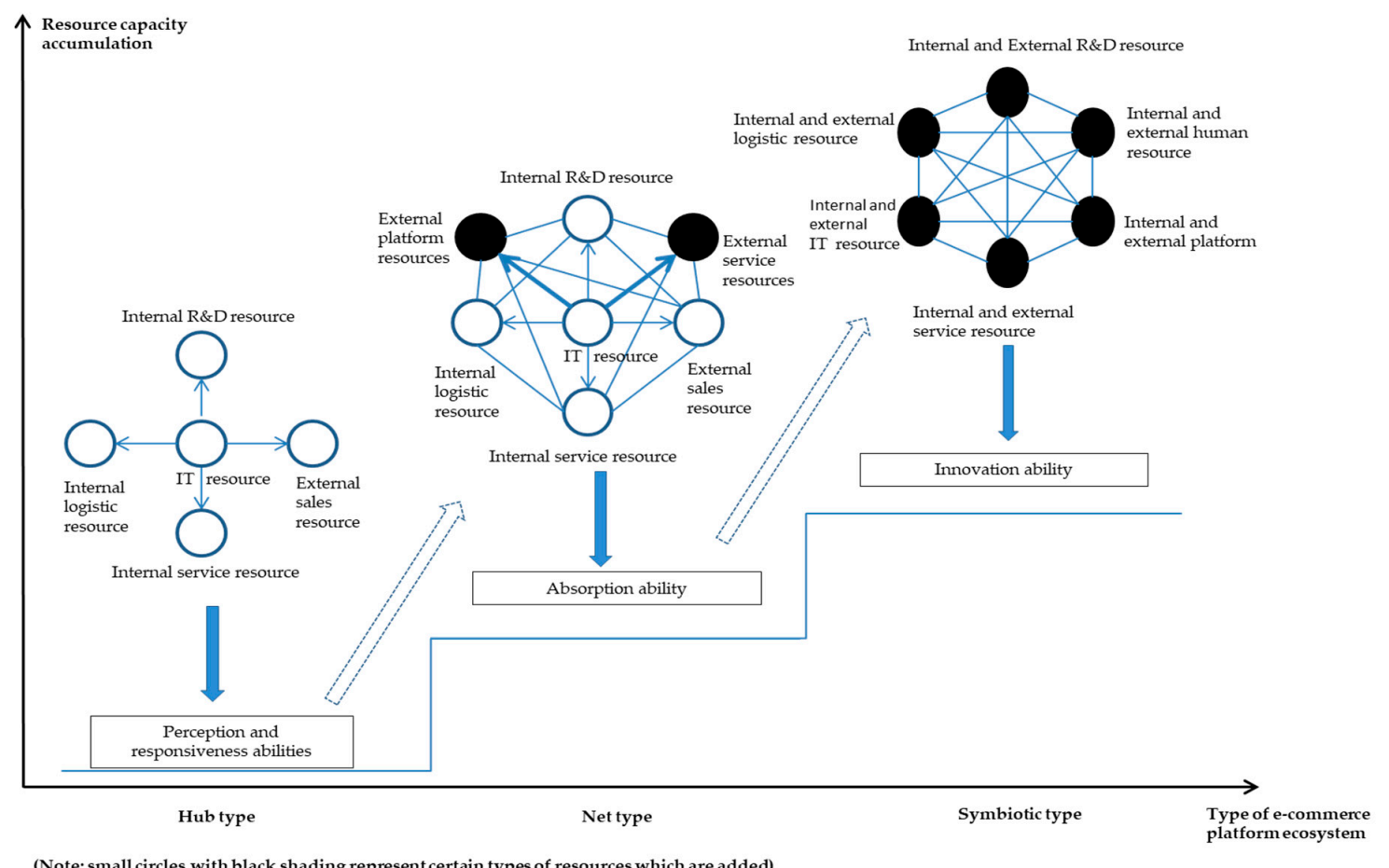

Figure 6. Resource combination and core competence jointly promote the construction mechanism of the sustainable e-commerce platform development.

5.3. Co-Creating Value Is the Internal Driving Force of Resource Orchestration to Promote the Construction of the Sustainable E-Commerce Platform Development of Manufacturing Enterprises

The function of Haier's sustainable e-commerce platform is transformed from the sales channel at the very beginning to the innovation incubation. In the background of industry 4.0, it has become a trend for manufacturing enterprises to construct sustainable e-commerce platform development, which is characterized by flexible and dynamic co-creation value to realize the personalized customization of users and the visualization of the whole process [44]. As co-creating value has become a two-way collaborative drive between users and sustainable platform manufacturers, it is no longer just a "user-driven theory" in the vertical integration value chain [45]. Nowadays, with the diversification of the value transfer of user demand, users have become the heterogeneity and unique resource of manufacturing enterprises' sustainable development. The two-way drive of manufacturing enterprises 
and user demand are the sources of the entire value creation, which plays a crucial role in sustainable product innovation.

"We attach great importance to users' comments and satisfaction on sustainable e-commerce, which is a way to grasp the pulse of the times... as long as customers put forward demands, Haier will integrate manufacturing sustainable development technology and other resources globally, and find new market opportunities through interaction with users. After RED and sales, we will continuously iterate and optimize products and services based on feedback."

-Vice President of Haier Group

In the background of a sustainable ecosystem, value is the co-creation by interaction and cooperation of manufacturing enterprises and users. Under the pull of user demand, Haier goes through an internal system, coordinates the internal and external resources to deliver satisfactory services, and interacts with users in the sustainable development and design of new products or the provision of solutions. This enables Haier to gradually establish user-centered "fan" co-governance and "small and micro" self-control organizations, and continuously expand the entire sustainable value creation system to promote e-commerce platform construction from early simple to multilateral symbiotic platform ecology.

\section{Conclusions}

The sustainable development of manufacturing enterprises realizes continuous transformation and upgrading through the e-commerce platform. Haier and Nuctech are not only different from the large-scale sustainable development mode of modern manufacturing enterprises like Red Collar and GDU, but also different from the e-commerce platform-based mode of Internet enterprises. Therefore, the case is significant both in theory and policy.

\subsection{Theoretical Contribution}

Firstly, the paper discusses the structure of a sustainable e-commerce platform based on the main characteristics of each resource. Previous literature mostly focuses on the management research on platform pricing mechanism and platform openness [2,46], and pays more attention to the promotion and hindrance factors or trust mechanism [47]. With a sustainable e-commerce platform function developed from the sales channels, and service differentiation to the innovation incubation, this paper systematically identified the characteristics and results of e-commerce platforms at different stages of sustainable development from the perspectives of resource orchestration. It expanded the research perspective of e-commerce platforms, and supplemented and developed the sustainable platform ecosystem theory.

Secondly, this paper systematically explored the mechanism and evolutionary driving force of resource orchestration to promote the construction of a sustainable e-commerce platform. Although existing studies also acknowledge the importance of resources to the sustainable development capabilities of manufacturers such as e-commerce $[9,48]$, they do not deeply think about the underlying mechanism. Combined with the dynamic characteristics of the external environment and managers' behaviors, this paper finds out that the manufacturing enterprise can acquire different core abilities to cope with the challenges of a rapidly changing environment. At the same time, manufacturing enterprises promote the evolution of e-commerce platforms in different sustainable development stages by constantly driving users in both directions, revealing the internal driving force of value creation in the development of e-commerce platforms. Therefore, this study is a supplement to the current value chain theory that pays more attention to vertical integration, and especially the in-depth application of the value creation theory of virtual integration in the Internet era [49]. It makes the theory of sustainable e-commerce platform development more profound and rich, which will further open the "black box" of development and evolution. 
Thirdly, this paper supplements the relevant theoretical and empirical research on resource orchestration, making an in-depth analysis of the connotation of resource orchestration and the specific application in different stages of sustainable development. In addition, although the resource orchestration theory emphasizes the importance of construction and utilization ability [25], the existing literatures have not conducted in-depth studies on what kind of core capacity to construct after the combination of resources. Therefore, this paper makes the resource orchestration theory more profound, also broadens the research scope of "resource orchestration" proposed by Sirmon et al. [10], and promotes the further sustainable development of related theories of resource orchestration of e-commerce.

\subsection{Managerial Implications}

The sustainable development of manufacturing enterprises needs to constantly cope with the dynamic environment through resource orchestration. We all know some manufacturing enterprises lose their competitive advantages and even withdraw from the historical trend under the background of the new era. Kodak, Motorola and Nokia, which all fell from the position of world hegemony in a very short time, provide a good reference for other manufacturing enterprises' sustainable development. The study shows that although unique and heterogeneous resources are very important for the development of manufacturing enterprises, the government also needs to be able to timely adjust its own resources on policies according to the changing dynamic environment [50]. In the developing process of sustainable e-commerce platforms, manufacturing enterprises need to be driven by internal managers and external users to orchestrate resources and construct appropriate core capabilities.

\subsection{Limitations and Future Research}

Resource orchestration constructs the core capability of transformation and upgrading of manufacturing enterprises' sustainable development. Though the structural behaviors such as acquisition, enrichment and so on, these resource orchestration behaviors are complementary and can occur at the same time in the process. According to their own situation and user feedback, managers can decide whether they should enrich current capabilities to satisfy users, or whether they need new resources to construct new capabilities. Future research can consider using quantitative analysis for hypothesis-driven tests so that the model of manufacturing enterprises constructing e-commerce platforms in the sustainable development ecosystem can be improved, with its restrictive conditions identified.

Author Contributions: Research design and writing, J.H., T.O., W.X.W. and J.C.; literature review, J.H.; case study firm interviewing, T.O. and J.C.; data analysis, J.H. and W.X.W. All authors have read and agreed to the published version of the manuscript.

Funding: This research was funded by the National Natural Science Foundation of China, grant number (71529001, 71632003, 71972008).

Conflicts of Interest: The authors declare no conflict of interest.

\section{References}

1. Zhao, Y.; Zhou, Y.; Deng, W. Innovation mode and optimization strategy of B2C e-commerce logistics distribution under big data. Sustainability 2020, 12, 3381. [CrossRef]

2. Li, C.; Liu, J.R.; Liu, Z.G.; Luo, X.G. Sustainable business model based on digital twin platform network: The inspiration from Haier's case study in China. Sustainability 2020, 12, 936. [CrossRef]

3. Leong, C.M.L.; Pan, S.L.; Newell, S.; Cui, L. The emergence of self-organizing e-commerce ecosystems in remote villages of China: A tale of digital empowerment for rural development. MIS Quart. 2016, 40, 475-484. [CrossRef]

4. Inoue, Y.; Hashimoto, M.; Takenaka, T. Effectiveness of ecosystem strategies for the sustainability of marketplace platform ecosystems. Sustainability 2019, 11, 5866. [CrossRef] 
5. Tan, B.; Pan, S.L.; Lu, X.; Huang, L. The role of IS capabilities in the development of multi-sided platforms: The digital ecosystem strategy of Alibaba. com. J. Assoc. Inf. Syst. 2015, 16, 248-281. [CrossRef]

6. Adner, R. Ecosystem as structure: An actionable construct for strategy. J. Manag. 2017, 43, 39-58. [CrossRef]

7. Cui, M.; Pan, S.L. Developing focal capabilities for e-commerce adoption: A resource orchestration perspective. Inf. Manage. 2015, 52, 200-209. [CrossRef]

8. Dandan, H.; Zhongfu, L.; Chunlin, W. An e-commerce platform for industrialized construction procurement based on BIM and linked data. Sustainability 2018, 10, 2613.

9. Jiang, S.; Hu, Y.; Wang, Z. Core firm based view on the mechanism of constructing an enterprise innovation ecosystem: A case study of Haier Group. Sustainability 2019, 11, 3108. [CrossRef]

10. Sirmon, D.G.; Hitt, M.A.; Ireland, R.D.; Gilbert, B.A. Resource orchestration to create competitive advantage: Breadth, depth, and life cycle effects. J. Manag. 2011, 37, 1390-1412. [CrossRef]

11. Armstrong, M. Competition in two-sided markets. RAND J. Econ. 2006, 37, 668-691. [CrossRef]

12. Rochet, J.C.; Tirole, J. Platform competition in two-sided markets. J. Eur. Econ. Assoc. 2003, 1, 990-1029. [CrossRef]

13. Belleflamme, P.; Peitz, M. Managing Competition on a Two-Sided Platform. J. Econ. Manag. Strat. 2019, 28, 5-22. [CrossRef]

14. Zeng, D.; Hu, J.; Ouyang, T. Managing Innovation Paradox in the Sustainable Innovation Ecosystem: A Case Study of Ambidextrous Capability in a Focal Firm. Sustainability 2017, 9, 2091. [CrossRef]

15. Choi, J.P.; Zennyo, Y. Platform market competition with endogenous side decisions. J. Econ. Manag. Strat. 2019, 28, 73-88. [CrossRef]

16. Bakos, J.Y. A strategic analysis of electronic marketplaces. MIS Quart. 1991, 15, 295-310. [CrossRef]

17. Van den Broeke, M.M.; Boute, R.N.; Van Mieghem, J.A. Platform flexibility strategies: R\&D investment versus production customization tradeoff. Eur. J. Oper. Res. 2018, 270, 475-486.

18. Mäkinen, S.J.; Kanniainen, J.; Peltola, I. Investigating adoption of free beta applications in a platform-based business ecosystem. J. Prod. Innovat. Manag. 2014, 31, 451-465. [CrossRef]

19. Deng, Z.; Wang, Z. Early-mover advantages at cross-border business-to-business e-commerce portals. J. Bus. Res. 2016, 69, 6002-6011. [CrossRef]

20. Li, S.S.; Karahanna, E. Online recommendation systems in a B2C e-commerce context: A review and future directions. J. Assoc. Inf. Syst. 2015, 16, 72-91. [CrossRef]

21. Miao, C.; Coombs, J.E.; Qian, S.; Sirmon, D.G. The mediating role of entrepreneurial orientation: A meta-analysis of resource orchestration and cultural contingencies. J. Bus. Res. 2017, 77, 68-80. [CrossRef]

22. Barney, J. Firm resources and sustained competitive advantage. J. Manag. 1991, 17, 99-120. [CrossRef]

23. Kozlenkova, I.V.; Samaha, S.A.; Palmatier, R.W. Resource-based theory in marketing. J. Acad. Market. Sci. 2014, 42, 1-21. [CrossRef]

24. Yi, Y.; Li, Y.; Hitt, M.A.; Liu, Y.; Wei, Z. The influence of resource bundling on the speed of strategic change: Moderating effects of relational capital. Asia Pac. J. Manag. 2016, 33, 435-467. [CrossRef]

25. Sirmon, D.G.; Hitt, M.A.; Ireland, R.D. Managing firm resources in dynamic environments to create value: Looking inside the black box. Acad. Manage. Rev. 2007, 32, 273-292. [CrossRef]

26. Helfat, C.E.; Finkelstein, S.; Mitchell, W.; Peteraf, M.; Singh, H.; Teece, D.; Winter, S.G. Dynamic Capabilities: Understanding Strategic Change in Organizations; John Wiley \& Sons: Hoboken, NJ, USA, 2009.

27. Schriber, S.; Löwstedt, J. Managing asset orchestration: A processual approach to adapting to dynamic environments. J. Bus. Res. 2018, 90, 307-317. [CrossRef]

28. Miguel, D.D.; Menchero, T.B.; Esteban-Navarro, M.N. Proximity trade and urban sustainability: Small retailers' expectations towards local online marketplaces. Sustainability 2019, 11, 7199. [CrossRef]

29. Hancock, D.R.; Algozzine, B. Doing Case Study Research: A Practical Guide for Beginning Researchers; Teachers College Press: New York, NY, USA, 2016.

30. Eisenhardt, K.M.; Graebner, M.E. Theory building from cases: Opportunities and challenges. Acad. Manag. J. 2007, 50, 25-32. [CrossRef]

31. Patton, M.Q. How to Use Qualitative Methods in Evaluation (No. 4); Sage: Thousand Oaks, CA, USA, 1987.

32. Glaser, B.G.; Strauss, A.L. Discovery of Grounded Theory: Strategies for Qualitative Research; Routledge: New York, NY, USA, 2017.

33. Eisenhardt, K.M. Building theories from case study research. Acad. Manag. Rev. 1989, 14, 532-550. [CrossRef] 
34. Pan, S.L.; Tan, B. Demystifying case research: A structured-pragmatic-situational (SPS) approach to conducting case studies. Inform. Organ. 2011, 21, 161-176. [CrossRef]

35. Corbin, J.; Strauss, A. Grounded theory research: Procedures, canons, and evaluative criteria. Qual. Sociol. 1990, 19, 418-427.

36. Gupta, A.; Briscoe, F.; Hambrick, D.C. Evenhandedness in resource allocation: Its relationship with CEO ideology, organizational discretion, and firm performance. Acad. Manag. J. 2018, 61, 1848-1868. [CrossRef]

37. Van Alstyne, M.W.; Parker, G.G.; Choudary, S.P. Pipelines, platforms, and the new rules of strategy. Harv. Bus. Rev. 2016, 94, 54-62.

38. Boyer, J. Toward an evolutionary and sustainability perspective of the innovation ecosystem: Revisiting the panarchy model. Sustainability 2020, 12, 3232. [CrossRef]

39. Fan, Y.; Ju, J.; Xiao, M. Reputation premium and reputation management: Evidence from the largest e-commerce platform in China. Int. J. Ind. Organ. 2016, 46, 63-76. [CrossRef]

40. Wang, W.T.; Wang, Y.S.; Liu, E.R. The stickiness intention of group-buying websites: The integration of the commitment-trust theory and e-commerce success model. Inform. Manag. 2016, 53, 625-642. [CrossRef]

41. Muller, J.; Kiel, D.; Voigt, K. What drives the implementation of Industry 4.0? The role of opportunities and challenges in the context of sustainability. Sustainability 2018, 10, 247. [CrossRef]

42. Felin, T.; Powell, T.C. Designing organizations for dynamic capabilities. Calif. Manag. Rev. 2016, 58, 78-96. [CrossRef]

43. Frynas, J.G.; Mol, M.J.; Mellahi, K. Management innovation made in China: Haier's Rendanheyi. Calif. Manag. Rev. 2018, 61, 71-93. [CrossRef]

44. Xu, X.; Wang, L.; Zhao, K. Exploring determinants of consumers' platform usage in “Double Eleven" shopping carnival in China: Cognition and emotion from an integrated perspective. Sustainability 2020, 12, 2790. [CrossRef]

45. Ranjan, K.R.; Read, S. Value co-creation: Concept and measurement. J. Acad. Market. Sci. 2016, 44, $290-315$. [CrossRef]

46. Tantalo, C.; Priem, R.L. Value creation through stakeholder synergy. Strateg. Manag. J. 2016, 37, $314-329$. [CrossRef]

47. Crossler, R.E.; Posey, C. Robbing Peter to pay Paul: Surrendering privacy for security's sake in an identity ecosystem. J. Assoc. Inf. Syst. 2017, 18, 487-515. [CrossRef]

48. Chandna, V.; Salimath, M.S. Peer-to-peer selling in online platforms: A salient business model for virtual entrepreneurship. J. Bus. Res. 2018, 84, 162-174. [CrossRef]

49. Porter, M.E.; Heppelmann, J.E. How smart, connected products are transforming competition. Har. Bus. Rev. 2014, 92, 64-88.

50. Zhou, Q.; Chen, X.; Li, S. Innovative Financial Approach for Agricultural Sustainability: A Case Study of Alibaba. Sustainability 2018, 10, 891. [CrossRef] 